\title{
Reverberações simbólicas no Google Trends: uma análise do imaginário na internet
}

\author{
Malena Segura Contrera \\ Universidade Paulista, Programa de Pós-Graduação em Comunicação, São Paulo, SP, Brasil \\ ORCID: https://orcid.org/0000-0003-4334-9467

\section{Leonardo Souza Torres} \\ Universidade Paulista, Programa de Pós-Graduação em Comunicação, São Paulo, SP, Brasil \\ ORCID: https://orcid.org/0000-0002-0511-8775
}

\begin{abstract}
Resumo
O texto propõe uma análise dos termos mais pesquisados da plataforma Google nos últimos dez anos, visando mapear, pela ferramenta Google Trends, a irrupção de conteúdos do imaginário na comunicação em rede. Buscou-se uma adaptação da proposta de Mitodologia de Gilbert Durand para se identificar o mito que irrompe na mídia eletrônica. A partir desses dados levantados, propôs-se uma reflexão sobre o Arquétipo de Tânatos e seus desdobramentos simbólicos para a sociedade mediática, questionando acerca do papel dos meios de comunicação e das práticas comunicativas nesse cenário cultural que elege a morte como seu símbolo diretor. Recorreuse às contribuições da Teoria do Imaginário, Teoria da Comunicação e da Mídia, estabelecendo cruzamentos teóricos que nos forneçam ferramentas cognitivas para pensar a contemporaneidade.
\end{abstract}

\section{Palavras-chave}

Imaginário; Arquétipo; Google Trends; Símbolo; Tânatos

\section{Introdução}

Atualmente, a média diária de consumo de internet por usuário no mundo é de 8 horas. Já no Brasil, são 9 horas diárias (KEMP, 2018). Somente o Google, site de pesquisa, agrega cerca de dois bilhões de usuários pelo mundo (MEEKER, 2018). A própria empresa (STEP..., 2014) afirma que eles recebem um tráfego de 450 milhões de pesquisas diariamente em seu site. E ainda, a plataforma Google é líder no segmento de buscas na internet (MEEKER, 2018). 
Sabendo disso, Seifter e outros (2010), desenvolveram um trabalho elucidando que uma análise das pesquisas do Google poderia prever epidemias de doenças, visto que existe uma tendência dos usuários, quando preocupados com sua saúde, a pesquisarem primeiramente seus sintomas no Google antes de se encaminharem para um profissional da saúde. Por exemplo, os termos "tosse" e "gripe" são mais pesquisados no inverno, isto é, em épocas mais propensas a epidemias.

A análise de pesquisas do site Google, pode ser feita pela ferramenta Google Trends (GOOGLE, [2021a]), cujos gráficos ilustram, em números relativos, a recorrência e a relevância dos termos inseridos no site Google. A plataforma do Google Trends revela dados entre os períodos 2001 e 2018, em âmbito de usuários mundiais, independente da língua pesquisada, quando pesquisada na modalidade "Assunto". Exemplificando:

Os Assuntos [termos] são um grupo de termos que compartilham o mesmo conceito em qualquer idioma. Se você pesquisar o assunto "London", sua pesquisa incluirá os resultados: "Capital do Reino Unido" "Londres", que é "London" em espanhol. (GOOGLE, [2021b], on-line, tradução nossa).

Entretanto, Seifter et al. (2010) afirmam que a ferramenta Google Trends carece de precisão (CHOI; VARIAN, 2009; LAZER, 2013), pois, na última década, comparando os números entre o G. Trends e os dados do Centro de Controle de Doenças (CDC) de respectivos países, o Trends revelou uma previsão epidemiológica duas vezes maior do que os registros dos CDCs (figura 1) LAZER et al., 2014).

Figura 1 - Discrepância GFT e CDC
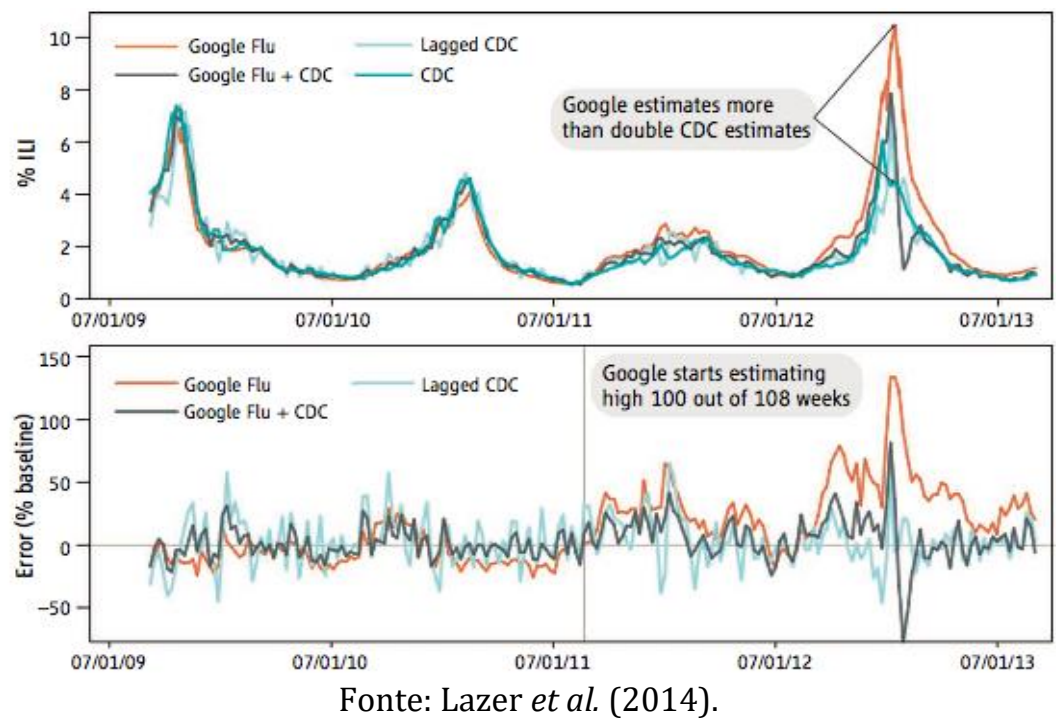
Apesar de a conclusão dos autores ser consistente, deve-se também discutir suas análises. Poderíamos considerar que a interpretação de Seifter et al. (2010) e Lazer et al. (2014) sobre o G. Trends é equivocada, porque o Google Trends não revela a ocorrência das doenças ou dos sintomas dos usuários, mas o estado psíquico coletivo gerado por elas, como o medo, o pânico, a preocupação, a curiosidade etc. Nesse contexto, a relação Google/usuário é comparável à relação médico/enfermo, ou ainda à relação tradicional entre Oráculo e consulente, como investigado por Miklos (2012), que diagnostica a existência de uma percepção social de que o Google seja onisciente. Estamos tratando de situações em que há uma angústia humana que faz indivíduos buscarem respostas, previsões, etc. Os próprios Seifter et al. (2010) e Lazer et al. (2014) foram envolvidos pelo sentido oracular da ferramenta quando afirmam que é possível, por meio do Google, prever as enfermidades na população mundial. Portanto, apesar de os resultados do Google Trends não serem tão satisfatórios para a epidemiologia, eles interessam aos Estudos do Imaginário e também à Psicologia das Massas.

Para o primeiro, poder-se-ia revelar um núcleo simbólico dominante (BARROS, 2010; DURAND, 1997) que age e molda a sociedade, visto a importância da internet e do próprio Google na atualidade. Para tanto, o objetivo deste trabalho é elencar os dez termos mais pesquisados no site Google entre 2001(menor ano possível de prospecção dos dados do Google Trends) e 2018 (ano-limite do período pesquisado) e, após a identificação do arquétipo $^{1}$ que tem irrompido no imaginário nos últimos 17 anos, analisar o universo simbólico que ele abriga.

\section{Método}

Como feito em trabalho anterior (TORRES, 2018), o método utilizado é inspirado na metodologia de G. Durand², apud Barros (2010), quando esta a aplica aos estudos de Jornalismo, revelando como o Imaginário retroage na sociedade:

[...] é possível adaptar o método também aos discursos da Comunicação, utilizando-o como uma técnica de análise de conteúdo que busca identificar metáforas obsessivas ou mitemas - repetições metonímicas do

\footnotetext{
1 "O arquétipo é um elemento vazio e formal em si, nada mais sendo do que uma facultas praeformandi, uma possibilidade dada $a$ priori da forma da sua representação. 0 que é herdado não são as ideias, mas as formas, as quais sob esse aspecto particular correspondem aos instintos igualmente determinados por sua forma" (JUNG, 2014, p. 87). 0 arquétipo é um núcleo imagético, atrator e autônomo.

${ }^{2}$ DURAND, G. A imaginação simbólica. Lisboa: Edições 70, 2000. Apud Barros (2010).
} 
mito que é objeto da narração geral que se estuda, de modo que cada fragmento reflete o todo - em dado recorte de pesquisa. 0 jogo de redundâncias é importantíssimo quando se trabalha com imagens simbólicas porque num símbolo, como explica Durand (2000, p. 16), tanto significado quanto significante são infinitamente abertos. A redundância serve para corrigir a inadequação da encarnação concreta do símbolo. É pelo jogo de redundâncias que se detectam num texto as metáforas obsessivas acima mencionadas e se torna possível identificar [...]. (BARROS, 2010, p. 135-136).

Com isso, escolheu-se os 10 termos, na modalidade "Assunto" mais pesquisados na plataforma Google, de 2001 a 2018, excluindo os anos de 2008 e 2009 porque, em ambos os anos, o Google Trends não disponibilizou os 10 mais pesquisados. A partir do momento em que os termos foram revelados, averiguou-se seus contextos. Ao identificar os termos e seus contextos, foram criadas as cinco categorias 3 aqui apresentadas: Produções Audiovisuais (filmes, novelas, clipes e reality show); Jogos (olímpiadas; copas do mundo; games on-line); Vida das Celebridades (sucessos e boatos de celebridades); Tecnologia de Comunicação (sites; redes sociais; aparatos tecnológicos); e Morte (morte de celebridades; suicídios; terrorismo e catástrofes).

Apesar de qualquer categorização possuir limitações, atentou-se para os conteúdos centrais que justificam os termos que atingiram tal relevância nas pesquisas durante o ano, buscando uma classificação mais próxima ao sentido real. Por exemplo, "Robin Williams" foi o termo mais pesquisado no ano de 2014, contudo, sua relevância nada tem a ver com suas produções cinematográficas, mas com a sua morte, por isso, foi incluído na categoria "Morte".

Os games on-line, por sua vez, poderiam ser categorizados em "Tecnologia" ou também "Morte", já que estes, em seu enredo, envolvem terrorismo, catástrofes, assassinatos, entre outros. Entretanto, escolheu-se ainda os inserir na categoria “Jogos”, pois antes de tudo ele é um jogo. A própria falta de definição entre os termos também pode indicar uma correlação imaginária entre eles. Ou seja, as categorias "Tecnologia", "Jogos" e "Morte" poderiam estar relacionadas. Contudo, este trabalho centra-se na categoria mais relevante e recorrente revelada na análise dos resultados dos últimos anos. 


\section{Resultados e discussão}

A fim de esclarecer uma hierarquia de relevância entre os termos e as categorias, concedeu-se grau de 10 a 1 aos termos dos 10 mais pesquisados do G. Trends, sendo os primeiros lugares com peso maior e os de décimos lugares com menor peso. Feito isso, da categoria de maior relevância para a de menor relevância, temos:

1ํo - Tecnologia da Comunicação (221 pontos de relevância);

$2^{\circ}$ - Morte (216 pontos);

3 - Celebridades (206 pontos);

4 o - Jogos (130 pontos);

5o - Produções Audiovisuais (101 pontos).

Curioso é que se considerarmos apenas os anos entre 2001 e 2017 a categoria "Morte" estava em 3ํㅡㄹ Lugar, somente o ano de 2018 foi responsável por alavancá-la para o 2 o lugar no ranking:

1ำ - Tecnologia da Comunicação (221 pontos de relevância);

$2^{\circ}$ - Celebridades (201 pontos);

$3^{\text {o }}$ - Morte (189 pontos);

$4^{\circ}$ - Jogos (120 pontos);

5ำ - Produções Audiovisuais (95 pontos).

Uma análise completa dos termos foi realizada em trabalho anterior (TORRES, 2018), revelando que em todo o período de análise o arquétipo de Narciso dominou os usuários do Google, e consequentemente, de grande parte da sociedade que utiliza a Internet. Em síntese, descobriu-se que, nestes últimos 15 anos, a mídia seria o reflexo de Narciso (narcótico) que entorpece os "usuários", adictos da tecnologia (CONTRERA, 2017). A respeito da relação entre meios de comunicação e usuários, podemos afirmar que:

Contemporaneamente, vemos toda a complexidade da comunicação humana ser minimizada e a centralidade das trocas comunicativas e dos processos vinculares se deslocarem para a questão da apropriação ou não das tecnologias da comunicação. Transformamo-nos, triunfantes, em usuários, título que alegremente repartimos com os drogadictos. A consciência que se exerce sobre todo esse processo é tanto menor quanto mais eficientemente se há estabelecido essa programação... A ciência moderna propagou tanto a falácia de que enfim triunfávamos na investigação sobre a natureza humana que acreditamos piamente nisso. (CONTRERA, 2017, p. 86). 
Já o afogamento de Narciso, ou melhor, o suicídio do jovem, como afirma Brandão (1986), representa bem essa obsessão pelo tema da morte, pulsão de morte demonstrada pelo G. Trends, em números quantitativos, nos últimos anos. Obsessão que, por sua vez, apresenta-se de forma mais literal por meio das tragédias, catástrofes, terrorismos, suicídios e mortes em geral (gráfico 1). É sobre essa relação que este trabalho pretende discutir.

Se pensarmos, ainda que brevemente, acerca de como a mitologia grega apresenta a relação entre Eros e Tânatos, veremos que os mitos cosmogônicos gregos propõem que nosso mundo nasce ao mesmo tempo pela intervenção dessas duas grandes forças cósmicas que o geram. Eros representa o princípio da ligação, da conexão, do vínculo, daquilo que liga; Eros é aqui concebido no sentido mais profundo da ideia de relação, de encontrar caminhos, de encontros possíveis, aquilo que de alguma forma nos leva em busca de um movimento de encontrar algo - como uma pulsão.

Pensar a pulsão a partir de sua etimologia, como algo que pulsa, nos ajuda a encontrar um sentido mais profundo para as pulsões do que a visão patologizante pela qual sempre foram tratadas por grande parte da teoria psicológica. Tânatos sempre foi compreendido como morte, mas seu sentido também abriga a ideia de desvinculação, isolamento, separação, disjunção, tudo que se poderia entender, de alguma maneira, como corte.

Quando pensamos pulsão como essa força que movimenta, que atesta uma inquietação própria do que ainda vive, vemos como sua relação com Eros se torna imediata aquilo que quer encontrar, quer realizar, quer se manifestar no mundo de alguma maneira. A pulsão pulsa, e pulsar significa também uma contração e uma soltura, um movimento, algo que leva as coisas a se moverem. Toda a noção de pulsão nos leva à ideia do movimento. Nós não conseguimos imaginar a palavra "pulsão" e pensar numa coisa imóvel, ou ainda sedada.

Oposto a isso que quer se mover é o que poderíamos chamar de "pulsão de morte", e isso é Tânatos. Sobre esse processo de amortecimento, que em muitos momentos se aplica perfeitamente a usuários da mídia eletrônica que passam 6, 8 horas por dia na frente das telas (KEMP, 2018), com seus dedos sendo os únicos a se moverem (dígitos, digitalizadores), J. Hillman afirma que "por pecado 'mortal' refiro-me ao pecado do amortecimento" (HILLMAN, 1997, p. 113).

0 pecado mortal é justamente tentar amortecer ou sedar essa energia que pulsa, o desejo do vínculo, a ação de Eros.Apartados de Eros, praticantes de uma comunicação que não promove processos de vinculação, e que pouco acolhe as participações concretas 
corporais, ficamos entregues a Tânatos, e então dominam a cena as compulsões e as dependências que normalmente as acompanham, seja dependência de drogas lícitas e ilícitas, de consumo ou de tecnologias da comunicação.

A compulsão pode ser pensada como a pulsão que voltou pela porta de trás, irrupção do inconsciente, depois de expulsa pela porta da frente da sociedade tecnológica. Quando a pulsão se apresenta, quando Eros se apresenta, quando a vida quer viver e nós negamos isso sistematicamente (não apenas de vez em quando), estamos convidando Tânatos, essa pulsão de vida que se retrai para voltar como seu avesso, como compulsão, não raramente sentida e descrita como morte.

A compulsão é a pulsão que adoeceu por falta de expressão. A compulsão nos faz viver toda a impotência do nosso ego frente à força dos deuses, perante a qual toda a tentativa de controle racional fracassa, devolvendo-nos à condição humana da incompletude, da "penúria" (HILLMAN, 1997).

Isso nos faz considerar que, por trás da irrupção do arquétipo de Tânatos, apresentase mais uma vez o fenômeno da crise do vínculo e a senilização dos formatos e das práticas comunicativas contemporâneas. E essa irrupção está evidente a partir dos dados que os gráficos abaixo nos apresentam.

Gráfico 1 - Relevância e Recorrências das Categorias

\section{Relevância e Recorrência}

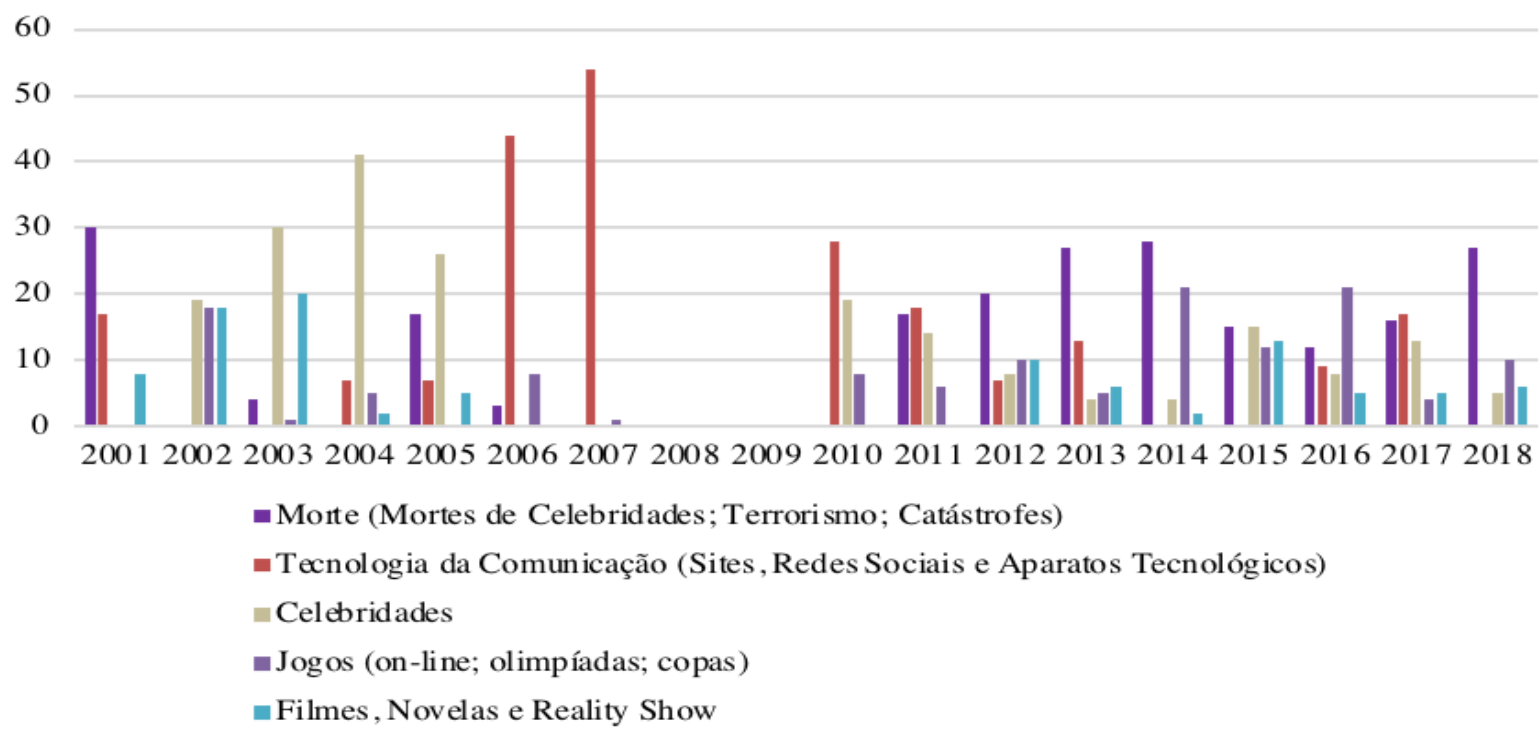

Fonte: Dados da pesquisa. 
Especificamente na categoria "Morte", no ano de 2018, 5 dos 10 termos mais pesquisados foram "mortes de celebridades". Houve aí um crescimento vertiginoso. Desde 2011 até 2014 esta categoria veio crescendo, reduzindo no ano de 2016 e voltando a crescer em 2017. Porém, nos últimos 7 anos, a categoria foi recorrente em todas as outras (jogos, celebridades filmes, redes sociais); em 4 anos ela ficou em primeiro lugar e nos restantes ela empatou ou ficou em segundo lugar comparada às outras categorias dos respectivos anos. Dentre as 5 categorias elencadas, ela foi a mais importante nos últimos 7 anos (gráfico 2).

Gráfico 2 - Relevância e Recorrências das Categorias

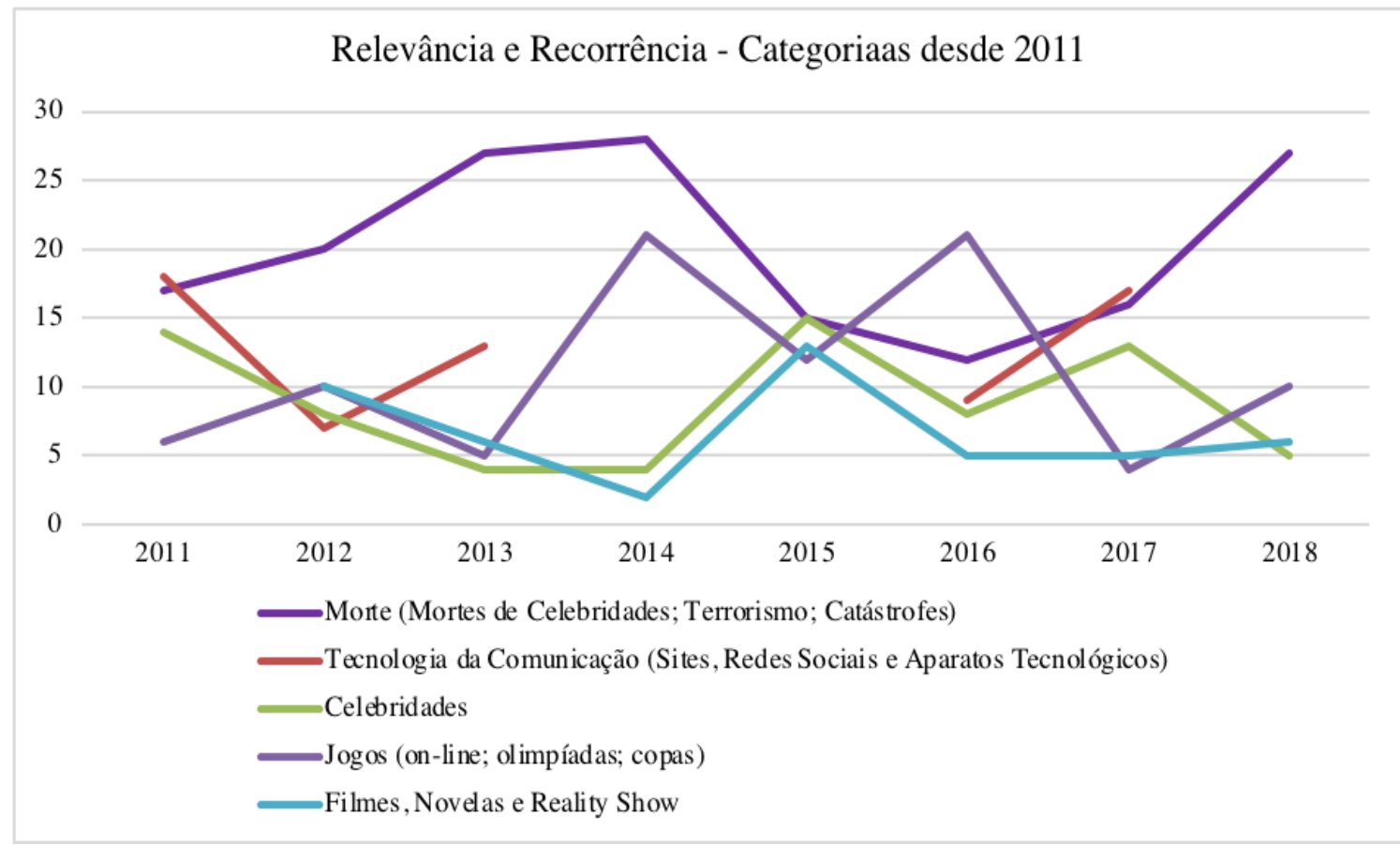

Fonte: Dados da pesquisa.

Sabemos que são necessários mais anos de análise para estarmos alinhados à mitocrítica proposta por G. Durand (1996) (que propõe, no mínimo, uma mudança de geração, isto é, 25 a 30 anos, ou um período secular, a cada 100 anos): "é assim que se passa de um trend (que significa corrente e cujo começo se faz ainda latentemente [...]) hercúleo, a um outro mercuriano, depois apolínio, prometeico, dionisíaco etc." (DURAND, 1996, p. 81107).

Dessa forma, esses dados apontam claramente para o crescimento de um padrão simbólico, e se pode entender que essa relevância e recorrência poderiam indicar o início da dominância de um arquétipo ligado à morte (gráfico 2); de qualquer forma, já se pode 
afirmar que os últimos 7 anos marcam uma tendência a um núcleo arquetípico relacionado à morte. Ou seja, os usuários do Google estão, por meio de suas buscas, migrando de um imaginário relativo a Narciso para um outro, relacionado a Tânatos.

\section{Tânatos e contágio Psíquico}

Conhecer a psique coletiva e seus temas dominantes é entender o caminho que a humanidade já traçou e está traçando no momento. Olharmos mais atentamente para os mitemas $^{4}$ dominantes (DURAND, 1997), para os deuses que se manifestam por meio da psique coletiva (JUNG, 2013), auxilia nossa compreensão dos comportamentos potenciais de um grupo, de uma sociedade, de uma nação.

[...] são modificações na constelação das dominantes psíquicas, dos arquétipos, dos "deuses", que causam ou acompanham transformações seculares da psique coletiva. Esta transformação tem alimentado dentro da tradição histórica e deixado as suas marcas. (Jung, 2013, p. 589).

Se no começo da análise do G. Trends as celebridades tomaram a cena da dominância psíquica, atualmente, as mortes delas as superaram. Porém a categoria vai além, comparecem também terrorismos, catástrofes e suicídios; os subtemas se mesclam, como o caso de Robin Williams, que se enquadra em "morte de uma celebridade" e "suicídio". 0 suicídio do ator impactou tanto a sociedade norte-americana que, conforme o estudo da Universidade de Columbia (FINK et al., 2018), entre agosto e dezembro de 2014, ano em que o ator cometeu suicídio, houve um crescimento de 9.85\% no índice de suicídio no país inteiro. De acordo com Reeves et al. (2014), outros fatores também podem influenciar comportamentos. Ao estudarem as taxas de suicídio na Europa e na América do Norte, afirmam que o índice de suicídio tem crescido ainda mais a partir da crise econômica no mundo no ano de 2008. Porém, este dado não foi possível de ser averiguado devido à não disponibilização no G. Trends.

Dessa forma, apesar de a discussão ser apontada a partir do ano de 2011, a Organização Mundial de Saúde (OMS, 2019a, 2019b) revela que, no último meio século, o índice de suicídios cresceu 60\% pelo mundo: em números, são mais de 800.000 indivíduos cometendo suicídio anualmente. Ele é a segunda causa de morte mais importante entre

\footnotetext{
${ }^{4}$ Neste caso, o conceito de mitemas dominantes aproxima-se com a ideia de dominância arquetípica de C. G. Jung.
} 
jovens de 15 a 29 anos no mundo (OMS, 2014) e cometê-lo é tão recorrente e está tão presente na vida do cidadão comum na contemporaneidade que Hillman afirma: "há maior probabilidade de o suicídio ocorrer no lar do que no hospício" (HILLMAN, 2011, p. 24).

Ademais, autores como Cheng et al. (2014) e Zimmerman et al. (2016) têm discorrido sobre algo que já sabíamos desde $O$ sofrimento do jovem Werther, de Goethe: o suicídio é contagioso e pode se tornar epidêmico. Desses estudos mais quantitativos e pontuais, é possível depreender que, por trás do modus vivendi da sociedade, estão os arquétipos dominantes que agem na psique coletiva; e os dados atuais nos levam a considerar que o rumo aponta para uma espécie de suicídio em massa. São casos, como já visto em trabalho anterior, de contágio psíquico (CONTRERA; TORRES, 2017).

Em outro estudo, constata-se que a hipótese de Tânatos como arquétipo dominante não é somente verificada pelos números de mortes literais, mas pelos produtos culturais e sociais que possuem como temática a figura do Zumbi. Filmes, séries, livros, quadrinhos, notícias, boatos, etc. surgiram na última década e têm se acentuado cada vez mais. Em trabalho anterior (CONTRERA; TORRES, 2017), ainda se comparou a figura do Vampiro com a do Zumbi no período de 2001 a 2017 por meio do Google Trends. Ambos são seres ligados à morte e à imortalidade. É curioso ter se verificado que a figura do Zumbi passa a ser mais relevante que a do Vampiro em 2012, ano subsequente e um dos primeiros em que a categoria da "Morte" apresentada neste trabalho ficou em 1ำ lugar de relevância quando comparada com as outras categorias no período aqui estipulado.

Em suma, a pulsão de morte predomina nas manifestações do imaginário mediático em nossa sociedade, e se faz presente desde os produtos culturais até os suicídios epidêmicos. Resta investigar mais a fundo esse arquétipo em busca de uma maior compreensão de suas características, para, por meio de nosso exercício de imaginação criativa, despotencializarmos o fascínio da possessão do arquétipo. Quem é, afinal, Tânatos, segundo o mito?

Tânatos, em grego $\Theta$ Enato $\$$ (Thánatos), tem como raiz o indo-europeu dhuen, "dissipar-se, extinguir-se". O sentido de "morrer", ao que parece, é uma inovação do grego. 0 morrer, no caso, significa ocultar-se, ser como sombra, uma vez que na Grécia o morto tornava-se eídolon, um como que retrato em sombras, um "corpo insubstancial". [...] Na iconografia antiga, Tânatos é representado por um túmulo, uma personagem armada com uma foice, um gênio alado, dois jovens, um preto, outro branco, um esqueleto, um cavaleiro, uma dança macabra, uma serpente, um animal psicopompo, como o cavalo, o cão. (BRANDÃo, 1986, p. 225-227). 
Baitello Junior (2005), ao pensar o fenômeno da Iconofagia, discorre sobre como o eídolon, a máscara mortuária, está intrinsecamente relacionada com as imagens produzidas pela mídia. Um dos graus da Iconofagia é a devoração do próprio indivíduo pela imagem. Mas vale também atentar para o "corpo insubstancial", o corpo sem substância, processo de abstração das relações concretas, que está na base do que temos chamado de rebaixamento de consciência, já tratado em trabalhos anteriores (CONTRERA, 2015).

Construímos o que venho chamando de consciência hipnógena (Contrera, 2012), intolerante ao princípio da realidade, avessa à dimensão concreta do mundo, esse lugar onde as coisas morrem e podem dar errado, onde as pedras são duras e não saem da nossa frente se não as empurrarmos montanha acima. Sísifo tentou nos ensinar, mas não entendemos nada. Cambaleantes e sem foco, os zumbis representam essa forma de consciência que não nos deixou transcender pelo meio da morte, mas que não nos deixou ancorar no mundo concreto, no corpo. (CONTRERA, 2015, p. 11).

Sobre a consciência hipnógena, vale lembrar que, conforme Brandão (1986), Hipno, "em grego pno\$ (Hýpnos), da raiz indo-européia suep, "aquietar-se, dormir", donde o latim "somnus" (BRANDÃO, 1986, p. 227) é irmão gêmeo de Tânatos. Na mitologia, Hipno é capaz de percorrer com rapidez todo o mundo e fazer todos os seres caírem no sono profundo. Brandão (1986) ainda discorre que Hipno se apaixona pelo pastor Endímion, dando ao pastor o dom de dormir com os olhos abertos, para que, quando Endímion dormisse, a divindade ainda pudesse olhar para seus olhos. Eis o estado zumbizógeno, ou de consciência hipnógena: estar adormecido com os olhos abertos. É evidente a aproximação da figura do Zumbi tanto com Hipno quanto com Tânatos.

Brandão (1986) afirma ainda que Tânatos possui coração de ferro e entranhas de bronze. Se vista da perspectiva do mundo contemporâneo, entendendo que a pulsão de morte está ligada ao modus vivendi do ser humano e à crise político-social mundial, pode-se aproximar Tânatos da metáfora de Max Weber (2012) quando este ilustra a contemporaneidade como um "habitáculo duro como aço":

Uma máquina sem vida é espírito que se congelou. Ora, é somente por ser isso que ela tem o poder de obrigar as pessoas a pôr-se a seu serviço, o poder de determinar e dominar o cotidiano de sua vida de trabalho, tão fortemente como o faz na fábrica. A máquina viva representada pela organização burocrática [...] também é espírito congelado. Em associação com a máquina morta, ela trabalha para fabricar o habitáculo dessa servidão dos tempos futuros, o qual um dia talvez, como os fellahs no 
Estado do Egito Antigo, as pessoas reduzidas à impotência serão obrigadas a vir ocupar [...] (WEBER, 2012, p. 29).

Portanto, o próprio modus operandi do turbocapitalismo neoliberal e a máquina burocratizadora do Estado possuem semelhanças com o mito de Tânatos. Estamos indiretamente falando sobre o processo de desmagicização do mundo, que institucionalizou as religiosidades, transformando-as em religiões de característica dupla: turbocapitalista e burocrática (Contrera, 2017; Weber, 2012). A mitologia romana ainda associa Tânatos, por meio de Hades, ao deus Plutão, deus dos mundos subterrâneos e dos tesouros, associado à riqueza material ${ }^{5}$.

Outra característica que Brandão (1986) aponta é que Tânatos não possui uma narrativa própria, mas aparece presente em diversos outros mitos, especialmente relacionado ao deus Hades, deus dos mundos subterrâneos. Esta presença de Tânatos em diversas narrativas míticas evidencia que ele faz parte de um núcleo bem antigo do imaginário ocidental. E é acerca do Ocidente que D. Kamper (2016) traz uma reflexão que relacionamos diretamente ao processo que aqui estamos apresentando, a Ocidentação: o caminhar para o crepúsculo, em meio a infinitas luzes midiáticas.

O mito de que, com a luz, pode-se festejar triunfo - triunfo sobre o corpo que vem do crepúsculo, do sol poente, da noite - foi desmentida em Hollywood e em Palo Alto. Através do iluminismo californiano, foram desapropriados o cérebro e o sexo de homens e mulheres. As últimas grandes descobertas na linha da mania de eternidade: a pílula e o computador, a pornografia e a corrida espacial afastaram o desejo corpóreo, destituíram-no do poder, esvaziaram-no e o abandonaram como um deserto. 0 deserto foi trapaceado e o mundo foi achatado em pura imagem de mundo. Com toda inocência, claro. Afinal, a florida juventude californiana, então ocupada com o consequente exagero da cisão cartesiana, estava totalmente sem noção. Em termos de emancipação, assim como o Scotty de Hitchcock, eles não entenderam nada do que estava acontecendo. (KAMPER, 2012, p. 25).

De acordo com Brandão (1986), se, por um lado, Tânatos não possui um mito próprio, por outro, ele é de extrema importância em Sísifo, outro mito que parece dialogar com o que estamos investigando. Sísifo escapou de Tânatos (da morte) por duas vezes, mas o trecho da narrativa que trata do destino final de Sísifo, ao procurar Tânatos pela terceira

\footnotetext{
${ }^{5}$ Essa relação entre deus e dinheiro está na base da Teologia da Prosperidade e talvez explique o fato veiculado pela revista FORBES, que apresenta o líder religioso Edir Macedo como um dos indivíduos mais ricos do mundo, somando uma fortuna de cerca de três bilhões de reais (FORBES, 2015). Parece que Thanatos dominou todas as instâncias da vida humana (a religião, as formas de produção, o corpo, as relações sociais).
} 
vez, remete-nos diretamente à crítica de Weber (2012) sobre a servidão das pessoas ao capitalismo:

Um dia, porém, Tânatos veio buscá-lo em definitivo e os deuses o castigaram impiedosamente, condenando-o a rolar um bloco de pedra montanha acima. Mal chegado ao cume, o bloco rola montanha abaixo, puxado por seu próprio peso. Sísifo recomeça a tarefa, que há de durar para sempre. (BRANDÃO, 1986, p. 227).

Não é a morte que esperava Sísifo, era o tormento, o martírio, a impossibilidade de morrer, na verdade, a imposição de seguir com um trabalho maquínico, para o qual ele não via sentido algum.

Brandão (1986) ainda aponta que, simbolicamente, Tânatos é a experiência da perecibilidade humana, do corpo, mas não apenas em sua natureza de bios, trata-se do corpo ctônico. Constantemente, e em diversas mitologias, Morte e Terra estão próximas simbolicamente, e Brandão afirma que tanto uma como a outra são símbolos de ritos de passagem que apontam para:

Revelação e Introdução, toda e qualquer iniciação passa por uma fase de morte, antes que as portas se abram para uma vida nova. Neste sentido, Tânatos contém um valor psicológico: extirpa as forças negativas e regressivas, ao mesmo tempo em que libera e desperta as energias espirituais. Filha da Noite e irmã de Hipno, o Sono, possui como sua mãe e irmã o poder de regenerar. Quando se abate sobre um ser, se este orientou sua vida apenas num sentido material, animalesco, a Morte o lançará nas trevas; se, pelo contrário, deixou-se guiar pela bússola do espírito, ela mesma lhe abrirá as cortinas que conduzem aos campos da luz. Não há dúvida de que em todos os níveis da vida humana coexistem a morte e a vida, ou seja, uma tensão entre forças contrárias, mas Tânatos pode ser a condição de ultrapassagem de um nível para um outro nível superior. Libertadora dos sofrimentos e preocupações, a Morte não é um fim em si; ela pode nos abrir as portas para o reino do espírito, para a vida verdadeira: mors ianua uitae, a morte é a porta da vida (BRANDÃO, 1986, p. 227).

\section{Conclusão}

O pensamento de Brandão (1986) possibilita que vejamos na presença de Tânatos no imaginário mediático não apenas uma pulsão de morte mera e simples, mas o final de um ciclo e a possibilidade de que se trate do início de um novo ciclo, sinalizando que estamos em pleno rito de passagem. Se Tânatos é destruição de um cosmos antigo, é revelação de um novo cosmos. Mas essa possibilidade exigirá que estejamos preparados para rever nossos 
modus pensandi (paradigmas e ideologias), vivendi (comportamentos sociais de habitação) $e$ operandi (sistema turbocapitalista).

O portal Earthovershootday (GLOBAL..., [2021]) aponta que a humanidade, no ano de 2018, utilizou uma quantidade de recursos da Terra que seria necessário 1.7 do planeta para suprir tal consumo. E, todo ano, desde 1970 (período de início das pesquisas do instituto), o consumo de recursos naturais extrapola o que a Terra pode nos oferecer, isto é, há 48 anos a humanidade está em débito ecológico com o planeta Terra. Harari (2018) ainda afirma que a atual crise ecológica tende a acelerar os avanços tecnológicos, e isso pode gerar consequências iguais às causadas pelas duas Guerras Mundiais do século passado. Além disso, o autor aponta que, se a humanidade continuar consumindo carne e praticando a monocultura da forma que tem feito, em poucos anos a Terra perderá sua diversidade, contando somente com animais como aves comestíveis, vacas, porcos e os pets e poucos tipos de vegetais.

Estamos sendo totalmente impotentes na tarefa de parar os processos causadores de profundos danos ecológicos que estão em ação e que, em questão de poucas décadas, irão se impor como um problema muito maior do que tudo com que pudemos lidar até agora - uma nova catástrofe planetária.

Talvez a irrupção de Tânatos no imaginário e na mídia esteja apenas nos sinalizando para a necessidade de trazer à consciência o que ocorre atualmente no mundo e nos preparar para o que virá nas próximas décadas.

\section{Financiamento}

A professora Dra Maria Helena Contrera possui financiamento pelo Conselho Nacional de Desenvolvimento Científico e Tecnológico (CNPq), como bolsista de Produtividade em Pesquisa 2.

\section{Referências}

BAITELLO JUNIOR., N. A era da iconofagia. São Paulo: Hacker, 2005.

BARROS, A. T. M. P. Comunicação e imaginário - uma proposta mitodológica. Intercom Revista Brasileira de Ciências da Comunicação, [s.l.], v. 33, n. 2, p. 125-143. jul./dez. São Paulo: 2010. 
BRANDÃO, J. Mitologia Grega. Petrópolis: Vozes, 1986. v. 1.

CHENG, Q., et al. Suicide contagion: a systemic review of definitions and research utility. PLOS Journals, São Francisco, 26 set. 2014.

CHOI, H.; VARIAN, H. Predicting the present with Google Trends. Economic Record, [s.l.], v. 88, p. 2-9, 27 jun. 2012.

CHOI, H.; VARIAN, H. Predicting initial claims for unemployment benefits. 2009. Disponível em: http://research.google.com/archive/papers/initialclaimsUS.pdf. Acesso em: 15 set. 2018.

CONTRERA, Ma. Mediosfera: meios, imaginários e desencantamento do mundo. 2ed. Porto Alegre: Imaginalis, 2017.

CONTRERA, M. Sobre zumbis, vampiros e seres da cultura mediática. Líbero, São Paulo, v. 18, n. 36, p. 9-14, jul-dez. 2015.

CONTRERA, M.; TORRES, L. Imaginário e contágio psíquico. Intexto, Porto Alegre, n. 40, p. 11-22, set./dez. 2017.

DURAND, G. As estruturas antropológicas do imaginário: introdução à arquetipologia geral. São Paulo: Martins Fontes, 1997.

DURAND, G. Champs de l'Imaginaire: textes réunis para Danièle Chauvin. Grenoble: Ellug, 1996.

GLOBAL FOOTPRINT NETWORK. Earth Overshoot day. [s.l.], [2021]. Disponível em: https://www.overshootday.org/about/. Acesso em: 7 fev. 2019.

FINK, D. S., et al.. Increase in suicides the months after the death of Robin Williams in the US. PLOS Jounals, São Francisco, 7 fev. 2018.

FORBER. \#1638 Edir Macedo \& family. [s.l.], 2 mar. 2015.

Disponível em: https://www.forbes.com/profile/edir-macedo/?sh=2b4509e02fcf. Acesso em: 8 fev. 2019.

STEP INSIDE ADWORDS LIVESTREAM. Google Small Business. [s.l.], 2014. 1 vídeo (29 min). Disponível em: https://www.youtube.com/watch?v=_5eXnF5RdFI. Acesso em: 20 set. 2018.

GOOGLE. Google Trends. [s.l.], [2021a].

Disponível em: trends.google.com.br/trends/?geo=BR.

GOOGLE. Google trends answer: [compare trends search terms]. [s.l.], [2021b]. Disponível em: https://support.google.com/trends/answer/4359550. Acesso em: 12 set. 2018.

HARARI, Y. N. 21 Lições para o Século 21. São Paulo: Companhia das Letras, 2018. 
HILLMAN, J. 0 código do ser: uma busca do caráter e da vocação pessoal. Rio de Janeiro: Objetiva, 1997.

HILLMAN, J. Suicídio e Alma. Petrópolis: Vozes, 2011.

KEMP, S. Digital in 2018: world's internet users pass the 4 billion mark [special reports]. In: WE ARE SOCIAL. We are social, New York: 30 jan. 2018.

JUNG, C. G. Um Mito Moderno Sobre Coisas Vistas no Céu. Rio de Janeiro: Editora Vozes, 2013.

JUNG, C. G. Os Arquétipos e o Inconsciente Coletivo. 11. ed. Petrópolis: Vozes, 2014.

KAMPER, D. Mudança de Horizonte: o sol novo a cada dia. Tradução Danielle Naves de Oliveira. São Paulo: Paulus, 2016.

KAMPER, D. Ocidentação: a direção do sol poente como forma de vida. Ghrebh, São Paulo, v. 1, n. 18, p. 20-31, out. 2012.

LAZER, D. et al. The Parable of Google Flu: traps in big data analysis. Science, [s.l.], v. 343, n. 6176, p. 1203-1205, mar. 2014.

MEEKER, M. Internet Trends 2018 Report. May 30th, 2018. Code Conference. Disponível em: https://pt.slideshare.net/kleinerperkins/internet-trends-report-2018-99574140 Acesso em: 01 set. 2018.

MIKLOS, J.. Ciber-religião: a construção de vínculos religiosos na cibercultura. 1a. ed. São Paulo: Ideias e Letras, 2012.

OMS. Suicide. [s/l], 2 set. 2019a. Disponível em: https://www.who.int/news-room/factsheets/detail/suicide. Acesso em: 20 set. 2018.

OMS. Mental health and substance use: suicide data. [s/l], 9 set. $2019 \mathrm{~b}$. Dispobível em: https://www.who.int/teams/mental-health-and-substance-use/suicide-data. Acesso em: 27 mar. 2018.

OMS. Preventing suicide: a global imperative. [s/l]: OMS, 2014. Disponível em: https://www.who.int/mental_health/suicide-prevention/world_report_2014/en/. Acesso em: 03 jan. 2019.

REEVES, A. et al.. Economic suicides in the Great Recession in Europe and North America. The British Journal of Psychiatry, London, v. 205, n. 3, p. 246-247, set. 2014.

SEIFTER, A. et al.. The utility of "Google Trends" for epidemiological research: Lyme disease as an example. Revista Geospatial Health. [s.l.], v. 4, n. 2, p. 135-137, 2010.

TORRES, L. Narciso afogado e o corpo apagado: contribuição terórica- metodológica para os estudos do imaginário a partir de uma mitologia do Google Trends. In: CONGRESSO 
INTERNACIONAL DE COMUNICAÇÃo E CULTURA, 6., 2018, São Paulo. Anais [...]. São Paulo: VI COMCULT, 2018.

ZIMMERMAN, G. M. The power of (mis)perception: rethinking suicide contagion in youth friendship networks. Social Science \& Medicine, [s.l.], n. 157. p. 31-38. 2016.

WEBER, M. A ética protestante e o espírito do capitalismo. São Paulo: Companhia das Letras, 2012.

\title{
Symbolic findings in Google Trends: an imaginary analysis of the internet
}

\begin{abstract}
The text proposes an analysis of the most searched terms of the Google platform in the last ten years, aiming to map, through the Google Trends tool, the eruption of imaginary content in network communication. An adaptation of Gilbert Durand's Mythology proposal was sought to identify the myth that erupts in the electronic media. From these collected data, it was proposed a reflection on the Thanatos Archetype and its symbolic developments for the media society, questioning about the role of the media and the communicative practices in this cultural scenario that elects death as its guiding symbol. We resorted to the contributions of the Theory of the Imaginary, Theory of Communication and the Media, establishing theoretical crossings that provide us with cognitive tools to think about contemporaneity.
\end{abstract}

\section{Keywords}

Imaginary; Archetype; Google Trends; Symbolic; Tânatos

\section{Autor correspondente}

Leonardo Souza Torres

leosouzatorres@gmail.com

\section{Como citar}

CONTRERA, Malena Segura; TORRES, Leonardo Souza. Reverberações Simbólicas no Google Trends: uma análise do imaginário na internet. Intexto, Porto Alegre, n. 52, e-98924, jan./dez. 2021.

DOI: http://dx.doi.org/10.19132/1807-8583202152.98924 